\title{
Editorial: \\ Designing, using and evaluating learning spaces: the generation of actionable knowledge
}

\author{
Paul Flynn \\ National University of Ireland, Galway
}

Kate Thompson

Griffith University

\section{Peter Goodyear}

The University of Sydney

\begin{abstract}
Digital educational technologies, like communication technologies more generally, can undermine the tyranny of distance. If we are not careful, we can slip into thinking that they make space and place irrelevant. This is not the case, as the papers in this special issue demonstrate. Technology needs to be understood as spatially configured and entangled with the material world. When people are using digital tools and resources in activities that lead to learning, place and the material qualities of things matter. This collection of papers introduces a diverse range of ways in which research can create actionable knowledge for those who need to make better decisions about the design and use of new learning spaces.
\end{abstract}

\section{Introduction}

The last few years have seen a welcome renaissance in research on innovative learning spaces. Researchers in Australasia are making substantial contributions to this growing field (e.g. Radcliffe, Wilson, Powell, \& Tibbetts, 2009; Blackmore, Bateman, Loughlin, O’Mara \& Aranda, 2011; Fisher, 2016; Imms, Cleveland \& Fisher, 2016; Acton, 2017; Ellis \& Goodyear, 2016, 2018). Much of the research and post-occupancy evaluation activity being reported takes place in schools, but there is also a significant strand of work on learning spaces in tertiary education settings. Paul Temple commented a decade ago on the surprisingly sparse nature of research on university learning spaces (Temple, 2008) and despite rapid adoption of new models for use of the built environment, university leaders still lack a reliable knowledge base for aligning their education, digital and estates decisions (Ellis \& Goodyear, 2019, esp. Chapter 5). As Jos Boys puts it:

\begin{abstract}
... we do not yet have effective tools for accurately mapping the dynamic intersections of pedagogies, spaces, access, ownership, timetabling, and cost in our existing or planned campuses; are not effectively integrating an understanding of pedagogic and scholarly activities with space and technology in university strategies and implementation processes; and have not yet developed sophisticated planning methods that can make value decisions across learning space performance and other demands such as sustainability, business and community partnerships, and so on. (Boys, 2015, 102)
\end{abstract}

In light of such pressing practical needs for actionable knowledge about the design, management, use and evaluation of learning spaces, this special issue of AJET is very timely. We have been fortunate in receiving some very high quality contributions, not all of which could find a home here. The six selected papers provide a good representation of research that is both use-inspired and theoretically interesting. But does it sit comfortably in an educational technology journal with a settled focus on things digital?

The easy answer is 'yes', but there is a more complex and challenging answer. We can assert an unqualified 'yes' because most new learning spaces, in universities and elsewhere, rely on significant use of digital technologies to function properly, and as Rose Luckin has demonstrated, the configuration of digital technologies in a material space can be crucial.

... the arrangement of the resources within a setting impacts upon the way that the resources are used to support learning within that setting ... the design of technology can influence a 
learner's interactions with the resources in their environment beyond those solely provided by the technology. (Luckin, 2010, 74, emphasis added)

While some of the marketing rhetoric around digital educational technology implies that space/distance are irrelevant, or can be made irrelevant, this is clearly not the case. Where learning takes place - where the student is - turns out to be consequential (Bayne, Gallagher \& Lamb, 2013; Carvalho, Goodyear \& de Laat, 2017; Gourlay \& Oliver, 2018). As some of the examples in this issue demonstrate, the interweaving of the digital and the material is becoming so complex and intricate that most learning spaces have to be seen as hybrid - as instances of 'digital materiality' (Yoo, 2012; Pink, Ardèvol, \& Lanzeni, 2016).

Understanding the complexity of tertiary learning spaces is non-trivial, as the needs of multiple stakeholders come together to enable learning. We cannot understand 'physical' learning spaces without reference to digital technologies; or 'digital' technologies without reference to sites of use. Those who do research in educational technology consider ideas about learning that are physically, digitally, socially, epistemically situated; and often challenging to share. Applying these ideas to learning, teaching and the design of learning spaces can help us to better understand the context in which teaching and learning occur, facilitating the sharing of practice, and promotion of learning for individuals and groups. The expertise in understanding relations between digital technologies and learning that has been built up over the years by ascilite members and in the pages of AJET is turning out to be a vital resource for architects, directors of estates, educational leaders and others who are currently reshaping university campuses.

The more complex answer emerges from a recognition that some of the conceptual work in learning spaces R\&D, and some of the redistributions of agency we find there - between designers, managers, teachers and students - can help shed new light on stubborn problems in educational technology.

In relation to theorisation and conceptual analysis, research on learning spaces has been expanding the repertoire of explanatory constructs linking designs, experiences and outcomes. It has been adding to Gibson's ecological psychology of perception and affordances a number of other constructs - from sociology, semiotics, architecture, design, anthropology and archaeology - that help build richer and more credible accounts of how people use, create, navigate, interpret and are influenced by tools and spaces (Bligh \& Crook, 2017; Goodyear, Ellis \& Marmot, 2018). These insights help us see that material qualities of tools and spaces really matter.

Moreover, the practices that have evolved around designing, creating, managing, customising, reconfiguring and otherwise using innovative learning spaces have created a body of experience in various forms of inclusive and participatory design. For recent examples, see Woolner (2015, Janssen, Könings \& van Merriënboer (2017, van Merriënboer, McKenney, Cullinan \& Heuer (2017), Yeoman \& Ashmore (this issue), and Marshalsey \& Sclater (this issue). Participatory design raises a number of important questions.

For example, it is reasonable to ask whether university students have the time, experience or inclination to invest significantly in shaping the learning spaces (and toolsets) that they and/or their peers are going to use. On the other hand, one can argue that the main point of having flexible, reconfigurable learning spaces is to give students opportunities to learn how to create congenial epistemic environments for their future work after graduation (Goodyear, 2019).

Involving teaching staff and students in the design of new learning spaces can turn out to be a surprisingly conservative process, with users asking for a slightly improved version of what they already know. In such cases, skilful scaffolding of participatory design processes can help teachers and students reach beyond their comfort zones (see e.g. Woolner, 2015; Yeoman \& Ashmore, this issue).

\section{Inside this special issue}

The six papers in this special issue examine different aspects of the relationships between physical space, teacher practice, learning, social interactions and community. They use a range of data sources: from observations, examination of design artefacts, questionnaires, focus groups and interviews with stakeholders. In combination, they make a significant contribution to our understanding of productive methodologies, forms of theorising and stakeholder perspectives on relations between space and learning. 
Some of the papers also foreground particular technologies, with ICT supporting the production of knowledge (e.g. Zeivots \& Schuck; Rooney \& Nyström) or connections between people (e.g. Carvalho et al.). We have sequenced the papers so that the reader can move between the perspectives of designers (Yeoman \& Ashmore), teachers (Mei \& May), and (postgraduate research) students (Zeivots \& Schuck and Carvalho et al.), and the issue concludes with two papers that examine profession-specific examples from health education (Rooney \& Nyström) and communication design (Marshalsey \& Sclater).

Yeoman \& Ashmore remark on the underdeveloped potential of theory as a source of actionable knowledge - an observation that can be applied to both educational technology (Oliver, 2013; Bulfin, Henderson \& Johnson, 2013) and the design of new learning spaces. They show how a sideways move to ergonomics can help inform some key decisions about the equipping and layout of novel learning spaces. They apply an activity-centred analysis and design framework (ACAD) to reframe conversations about desirable, but necessarily emergent, qualities of teaching and learning in these spaces, focussing especially on mobility, dialogue and connection. They address two particular design challenges: orchestrating learning in the round and combining co-present and remote participation in collaborative learning.

Mei \& May draw on secondary data collected from teachers to evaluate a Collaborative and Active Learning Space (CALS) project at the University of Auckland. They focus on six aspects of the learning space: flexible furniture, multiple screens, in-classroom iPads, dual display systems, enhancements to the wireless network and sound quality. Drawing on questionnaires and interviews, the authors identify attitudes towards the learning space in terms of supporting pedagogy and affording opportunities to experiment. The authors note that broader institutional support would have allowed teaching staff to consider the new space in terms of course design or in the preparation of students to learn in the space, and would have allowed strategic allocation of classes and teachers to the CALS.

Two papers (Carvalho et al. and Zeivots \& Schuck) focus on postgraduate research students and learning spaces. Both papers consider the needs of research students in terms of physical space, flexibility, coordination between multiple spaces, and the use of spaces to foster a sense of belonging and connection to other students. Carvalho et al.'s paper on the learning imaginaries of doctoral students uses in-depth interviews to explore student experiences of on-campus and other spaces for learning. Fluid movement, home bases, connection and identity emerge as important in these narratives. A key contribution from this paper is to show how students connect multiple sites, people, tools and resources in networks to support their personal learning and identity formation.

Zeivots \& Schuck discuss a newly designed postgraduate research student learning space at the University of Technology, Sydney. This space includes areas zoned for different kinds of use and social configurations (e.g. individual, quiet work or collaborative sharing of ideas). The space is flexible, in that students do not 'own' parts of it. The authors' analysis draws on case study and hermeneutic phenomenology. Students' voices are heard through online surveys, in-depth interviews and feedback emails. The paper traces some of the complexities and variations in research student life, revealing different implications for supportive spaces. Students need configurations of space and equipment appropriate for the specific learning and inquiry tasks they are tackling, but they also welcome spaces in which they feel connected to a larger community.

The last two papers focus on the role of space in the enactment of learning and teaching in particular disciplines/professions: health (Rooney \& Nyström) and design communication (Marshalsey \& Sclater). Rooney \& Nyström's paper explores pedagogies of simulation spaces in nursing, medical and other healthrelated education, adopting an ethnographic methodology, with non-participant observation, and applying a socio-material lens. They use layers to examine simulation spaces: the background, empirical (examining students' experiences of simulation spaces), and spatial injustices. They tease out relationships between activities, things and spaces, and the provision of opportunities for learning. They discuss the complex interplay of pedagogy and the material, to help those making decisions in and about complex learning environments.

Mashalsey \& Sclater's paper is based on the first author's doctoral studies in the specific context of Communication Design. The authors use participatory action research and visual ethnography, collecting drawings, sound recordings and sonic mapping, as well as questionnaire and focus group data. Two case studies are described - one a traditional Design Studio setting and the other a blended environment. In the 
first case, conventional studio-based learning spaces, with allocated work stations, in open-plan format, help students in the creation of an identity and a sense of belonging. The 'blended' case did not have these features, so students felt only a limited sense of belonging and instead created their own spaces in cafes and on social media.

We hope that this collection of papers will inspire colleagues in the educational technology community to look more closely at how technology becomes involved in educational place-making, and to find richer forms of explanation for the subtle relations linking learning, technology and location.

\section{Acknowledgements}

We are indebted to the reviewers of the numerous manuscripts submitted to this special issue and to the AJET editorial team and copyeditors for their support in bringing this special issue to fruition.

\section{References}

Acton, R. (2017). Place-people-practice-process: using sociomateriality in university physical spaces research. Educational Philosophy and Theory, 49(14), 1441-1451. doi:10.1080/00131857.2017.1309637

Bayne, S., Gallagher, M., \& Lamb, J. (2013). Being 'at' university: the social topologies of distance students. Higher Education, 67(5), 569-583. doi:10.1007/s10734-013-9662-4

Blackmore, J., Bateman, D., Loughlin, J., O’Mara, J., \& Aranda, G. (2011). Research into the connection between built learning spaces and student outcomes. East Melbourne, Victoria: Dept of Education and Early Childhood.

Bligh, B., \& Crook, C. (2017). Learning spaces. In E. Duval, M. Sharples, \& R. Sutherland (Eds.), Technology enhanced learning: research themes (pp. 69-88). Cham: Springer. doi:10.1007/978-3319-02600-8 7

Boys, J. (2015). Building better universities: strategies, spaces, technologies. New York: Routledge. doi: $10.4324 / 9780203798881$

Bulfin, S., Henderson, M., \& Johnson, N. (2013). Examining the use of theory within educational technology and media research. Learning, Media and Technology, 38(3), 337-344. doi:10.1080/17439884.2013.790315

Carvalho, L., Goodyear, P., \& de Laat, M. (Eds.). (2017). Place-based spaces for networked learning. New York: Routledge. doi:10.4324/9781315724485

Ellis, R., \& Goodyear, P. (2016). Models of learning space: integrating research on space, place and learning in higher education. Review of Education, 4(2), 149-191. doi:10.1002/rev3.3056

Ellis, R., \& Goodyear, P. (Eds.). (2018). Spaces of teaching and learning: integrating perspectives on research and practice. Singapore: Springer Nature. doi:10.1007/978-981-10-7155-3

Ellis, R., \& Goodyear, P. (2019). The education ecology of universities: integrating strategy, learning and the academy. Abingdon: Routledge.

Fisher, K. (Ed.) (2016). The translational design of schools: an evidence-based approach to aligning pedagogy and learning environments. Rotterdam: Sense. doi:10.1007/978-94-6300-364-3

Goodyear, P. (in press, 2019). Flexible learning spaces. In J. M. Spector (Ed.), Routledge Encyclopedia of Education. Abingdon: Routledge.

Goodyear, P., Ellis, R., \& Marmot, A. (2018). Learning spaces research: framing actionable knowledge. In R. Ellis \& P. Goodyear (Eds.), Spaces of teaching and learning: integrating perspectives on research and practice (pp. 221-238). Singapore: Springer Nature. doi:10.1007/978-981-10-7155-3_12

Gourlay, L., \& Oliver, M. (2018). Student engagement in the digital university: sociomaterial assemblages. New York: Routledge. doi:10.4324/9781315647524

Imms, W., Cleveland, B., \& Fisher, K. (Eds.). (2016). Evaluating learning environments: snapshots of emerging issues, methods and knowledge. Rotterdam: Sense. doi:10.1007/978-94-6300-537-1

Janssen, F. J., Könings, K. D., \& van Merriënboer, J. J. (2017). Participatory educational design: How to improve mutual learning and the quality and usability of the design? European Journal of Education, 52(3), 268-279. doi:10.1111/ejed.12229

Luckin, R. (2010). Re-designing learning contexts: technology-rich, learner-centred ecologies. New York: Routledge. doi:10.4324/9780203854754

Oliver, M. (2013). Learning technology: Theorising the tools we study. British Journal of Educational Technology, 44(1), doi:31-43. 10.1111/j.1467-8535.2011.01283.x 
Pink, S., Ardèvol, E., \& Lanzeni, D. (Eds.). (2016). Digital materialities: design and anthropology. London: Bloomsbury. doi:10.5040/9781474295789

Radcliffe, D., Wilson, H., Powell, D., \& Tibbetts, B. (2009). Designing next generation places of learning: collaboration at the pedagogy-space-technology nexus. Brisbane: University of Queensland

Temple, P. (2008). Learning spaces in higher education: an under-researched topic. London Review of Education, 6(3), 229-241. doi:10.1080/14748460802489363

van Merriënboer, J. J., McKenney, S., Cullinan, D., \& Heuer, J. (2017). Aligning pedagogy with physical learning spaces. European Journal of Education, 52(3), 253-267. doi:10.1111/ejed.12225

Woolner, P. (Ed.) (2015). School design together. London: Routledge. doi:10.4324/9781315774107

Yoo, Y. (2012). Digital materiality and the emergence of an evolutionary science of the artificial. In P. Leonardi, B. Nardi, \& J. Kallinikos (Eds.), Materiality and organizing: social interaction in a technological world (pp. 134-154). Oxford: Oxford University Press. doi:10.1093/acprof:oso/9780199664054.003.0007

Corresponding editor: Paul Flynn, paul.flynn@nuigalway.ie

Australasian Journal of Educational Technology (C) 2018.

Please cite as: Flynn, P., Thompson, K \& Goodyear, P. (2018). Designing, using and evaluating learning spaces: the generation of actionable knowledge. Australasian Journal of Educational Technology, 34(6), i-v. https://doi.org/10.14742/ajet.5091 